\title{
Роль нефинансовых ресурсов \\ в повышении капитализации страховой компании
}

\author{
Людмила Ивановна Цветкова \\ кандидат экономических наук, доцент \\ ORCID \\ E-mail: tsvetkova1501@gmail.com \\ Кафедра управления рисками и страхования, Московский государственный институт международных \\ отношений МИД РФ, Москва, Россия
}

Journal of Corporate Finance Research, Vol. 13, No. 2, pp. 66-80 (2019)

DOI: https://doi.org/10.17323/j.jcfr.2073-0438.13.2.2019.66-80

Поступила в редакцию 24 марта 2019 | Получена рецензия 10 апреля 2019 |

Принята к публикации 3 июня 2019 


\section{Роль нефинансовых ресурсов в повышении капитализации страховой компании}

\section{Аннотация}

В современных условиях потребность в росте капитализации страховой компании удовлетворяется в результате обеспечения достаточности капитала для поддержания страховой деятельности компании на определенном уровне и адекватности качества и структуры капитала. Она определяется с учетом номенклатуры предлагаемых компанией страховых продуктов и услуг, степени рисков, связанных со страховой и инвестиционной деятельностью компании, перспектив ее роста и др.

Целью статьи является проведение концептуального исследования по определению роли и места нефинансовых ресурсов в капитализации страховой компании на основе гипотезы, согласно которой превращение нефинансовых ресурсов в капитал происходит путем их объединения с предпринимательским ресурсом, его носителем выступает либо сам сотрудник, либо управляющий его трудом менеджер.

В ходе реализации исследования были использованы следующие методы: метод дедукции при схематическом построении архитектуры человеческих ресурсов и составляющих инструментария конкурентоспособности компании; метод индукции при определении элементов человеческого капитала; абстрагирование в процессе выявления трансформации нефинансовых ресурсов в финансовый капитал; анализ теоретических подходов в международном опыте страховой бизнес-практики.

Поиск структуры капитала страховой компании осуществлялся на основе ресурсной концепции конкурентоспособности и рассмотрения стейкхолдеров как поставщиков ресурсов компании, суммарное множество которых в конечном итоге воплощается в форму финансового капитала. Привлекаемые страховщиком ресурсы имеют ценность, поскольку могут быть трансформированы в форму финансовых активов (основных и оборотных), и в этой форме содействовать обеспечению интересов тех его стейкхолдеров, которые поставляют компании ресурсы в финансовой форме: страхователей и страховщиков. Эффективность структуры нефинансового капитала компании основана на ее способности порождать или трансформироваться в финансовый капитал.

В результате исследования были определены наступление стоимостной синергии как комбинации всех ресурсов страховой компании, а также необходимость внесения страховыми компаниями персонифицированных знаний в корпоративную стратегию как полноценного структурного элемента, через который развивается и пополняется инновационный капитал.

Результаты исследования могут быть внедрены в страховых компаниях как новый управленческий подход повышения эффективности деятельности и стратегической стабильности фирмы.

Ценность статьи заключается в разработке универсального практического инструментария по повышению капитализации независимо от рыночной специализации страховой компании.

Ключевые слова: ресурсный подход, нефинансовые ресурсы, инновации, предпринимательский капитал JEL classification: G34, M14, O16 


\section{Введение}

Потребность в росте капитализации страховой компании обусловлена двумя аспектами: достаточностью капитала для поддержания страховой деятельности компании на определенном уровне и адекватностью качества и структуры капитала.

Потребность в росте капитала учитывает номенклатуру предлагаемых компанией страховых продуктов и услуг, степень рисков, связанных со страховой и инвестиционной деятельностью компании, перспективы ее роста, необходимость финансовой поддержки дочерних компаний и выплаты дивидендов, объем финансовой задолженности, адекватность перестраховочных и общих резервов, а также наличие капитала для нейтрализации воздействия непредвиденных событий [1].

Устойчивость рынка страховых услуг во многом зависит от платежеспособности компаний, поэтому уход игроков из-за недостаточного капитала можно признать инструментом улучшения рыночной конъюнктуры, увеличивающим долю компаний, не испытывающих сложностей с исполнением обязательств перед клиентами только при условии, если иных инструментов обеспечения платежеспособности в их распоряжении просто нет.

Специфика сектора финансовых услуг заключается в том, что взаимоотношения между клиентами и компанией во многом зависят от уровня доверия, подрыв которого отражается на емкости рыночной ниши (потребитель отказывается от услуги из-за недоверия и не приносит деньги на рынок). Таким образом, развитие страхового рынка можно напрямую связывать не только с повышением капитализации, но и с ростом уровня сбалансированности страхового портфеля. Создание новых благ (капитальных), увеличивающих доходы собственников страхового дела на величину процента от вложений в бизнес, в наименьшей мере зависит от объема вложенного капитала и определяется ростом показателя отдачи на капитал, как повышения отношения сборов страховых премий к вложенному капиталу. Этот процесс свидетельствует о росте рыночной доли компании, соответственно увеличении прибыли и повышении рентабельности собственных средств. Кроме того, сбалансированный и существенный в части выборки страховой портфель приводит к снижению волатильности убытков, a, значит, и страховых тарифов. Рост рыночной доли приводит к росту стоимости компании и повышению благосостояния всех стейкхолдеров.

Ресурсная концепция конкурентоспособности и рассмотрение стейкхолдеров как поставщиков ресурсов компании позволяют сделать вывод о различной сущности ресурсов страховщика, суммарное множество которых в конечном итоге воплощается в форму финансового капитала. Привлекаемые страховщиком ресурсы имеют ценность, поскольку могут быть трансформированы в форму финансовых активов (основных и оборотных), и в этой форме содействовать обеспечению интересов тех его стейкхолдеров, которые поставляют компании ресурсы в финансовой форме: страхователей и страховщиков. В связи с этим возникает вопрос об эффективности структуры нефинансового капитала компании, в основе которой лежит способность порождать или трансформироваться в финансовый капитал.

Решение проблемы поиска структуры капитала страховой компании на основе ресурсного подхода впервые было предложено страховой компанией Skandia (Швеция), в лице ее Главного управляющего знанием - Л. Эдвинссона [2]. В качестве центральной модели структуры нефинансовых форм капитала были определены два основных компонента и их взаимодействие при создании стоимости:

- человеческий капитал, формируемый человеческими ресурсами фирмы.

Это совокупность знаний, практических навыков и творческих способностей служащих компании, приложенная к выполнению текущих задач. Другими его составляющими являются ценности компании, культура труда и общий подход к делу. Человеческий капитал не принадлежит компании, тогда как человеческие ресурсы как бы арендуются ею;

- структурный капитал.

В эту категорию входят техническое и программное обеспечение, организационная структура, патенты, торговые марки и все то, что позволяет работникам компании реализовать свой производственный потенциал, - иными словами, то, что остается в офисе после ухода служащих домой. Структурный капитал также включает капитал отношений, сложившихся между компанией и ее крупными клиентами. В отличие от человеческого капитала, структурный капитал может быть собственностью компании и, следовательно, объектом купли-продажи.

Согласно модели Skandia [3]

Человеческий капитал + Структурный капитал = = Интеллектуальный капитал.

При этом результатом взаимодействия данных элементов является обеспечение длительного сохранения успешного положения компании на рынке путем постоянного производства и коммерциализации инновационных решений. Л. Эдвинссон был согласен, что именно производство инноваций служит источником создания стоимости страховой услуги, формирующей ключевую компетенцию компании [4]. Такая позиция исходила из того, что у создания стоимости есть два фундаментальных источника.

Первый - это те инновации, которые генерируются человеческими ресурсами фирмы в юридически защищенные интеллектуальные активы. Вторым источником являются продукты и услуги, которые возникают в результате коммерциализации инноваций. 
Инновационные решения, реализуемые в рамках первого источника создания стоимости, касаются всех бизнес-процессов и их результатов вплоть до вывода страхового продукта на рынок. Второй же источник формирования стоимости связан с инновациями в продаже страховых продуктов, переводящих нефинансовый капитал в финансовую форму.

\section{Обзор литературы и гипотезы исследования}

Предпринимательский ресурс может быть представлен как совокупность функций, выполняемых им в социально-экономической системе. Это один из дискуссионных аспектов теории предпринимательства, по которому мнения исследователей расходятся.

Так, С.Э. Жилинский выделяет три функции:

- $\quad$ ресурсную, заключающуюся в нетрадиционном соединении факторов производства (земли, капитала, труда) и способствующую росту производства товаров и услуг, повышению эффективности экономики;

- организаторскую, состоящую в таком соединении и комбинировании факторов производства, которое наилучшим образом приведет к достижению корпоративной цели, получению высокого дохода;

- творческую, связанную с новациями [5].

М.Г. Лапуста, А.Г. Поршнев, Ю.Л. Старостин, Л.Г. Скамай считают, что предпринимательство выполняет общеэкономическую, творческо-поисковую (инновационную), ресурсную, социальную и организаторскую функции [6].

Изложенное выше позволяет выдвинуть следующую гипотезу: превращение нефинансовых ресурсов в капитал происходит путем их объединения с предпринимательским ресурсом, носителем которого является либо сам сотрудник, либо управляющий его трудом менеджер.

Интеллектуальный капитал страховой компании служит источником создания дополнительной стоимости, поскольку обеспечивает инновационные решения, создающие квазимонопольную сверхприбыль в период до начала процесса диффузии инновационных решений на рынке. В него же следует включить разработки инновационных решений и поиск предмета для инноваций, поскольку инновационный процесс не может быть остановлен, исходя из ограниченности жизненного цикла предприятия [7]. В соответствии со взглядами И. Адизеса, в основе жизненного цикла любой организации находится фундаментальный закон, гласящий, что все организации, как живые организмы, проходят через схожие стадии жизненного цикла и демонстрируют прогнозируемые и повторяющиеся модели поведения. На каждой новой стадии развития каждая организация сталкивается с уникальным набором вызовов и сложностей. Успех организации определяется способностью менеджеров управлять переходом от одной стадии к другой, а также проводить своевременное обновление стратегии во избежание экономической «смерти». Таким образом величина интеллектуального капитала может быть оценена доходным методом (по порождаемому доходу).

Интеллектуальный капитал по Л. Эдвинссону возникает в результате объединения всех нефинансовых ресурсов в единую структуру. Поскольку основную его ценность составляет способность производить инновационные решения, то в модель Skandia включен инновационный капитал (рис. 1).

Рисунок 1. Модель интеллектуального капитала как источника создания новой стоимости

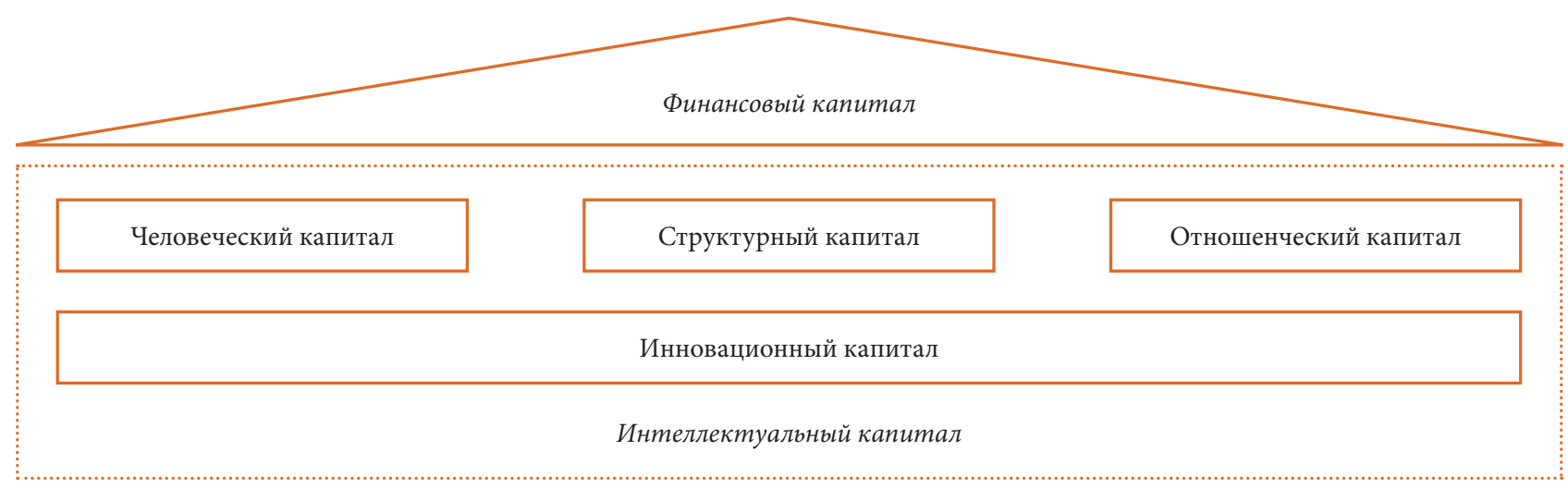

Источник: составлено на основе [8]. 
Представленная модель (см. рис. 1) логично выстраивает архитектуру между элементами, однако не показывает связь ряда элементов нефинансового капитала с порождающими их ресурсами. Структурный и отношенческий капиталы являются результатами операционной деятельности компании, поэтому отсутствие ясности, за счет каких ресурсов они создаются, порождает сложность в их разграничении и количественном определении.

Кроме того, модель не разъясняет, что имеется в виду под инновационным капиталом: инновационный потенциал, как способность компании к формулировке инновационных решений, или инновационные продукты, созданные с использованием инновационных решений.

Соотнесение нефинансовых форм капитала с порождающими их ресурсами имеет практическое значение для идентификации спектра необходимых ресурсов и оценки эффективности их привлечения. Категориальное определение привлекаемых ресурсов является условием финансовой оценки их стоимости, которая позволит оценить эффективность каждого ресурса путем соотнесения его с создаваемыми при его использовании долей финансового капитала. Все это обусловливает потребность усовершенствования модели Л. Эдвинссона путем интеграции ее аспектов инструментария формирования нефинансового капитала.

Человеческие, информационные и предпринимательские ресурсы могут рассматриваться как факторы производства. Если возможно их привлечение, значит, они имеют предметную форму, обеспечивающую их идентификацию. Ответ на вопрос, при каких условиях эти ресурсы становятся капиталом, следует искать в функциях предпринимательского ресурса. Предпринимательский ресурс, осуществляя свои функции, инициирует процессы производства или обмена, тем самым реализуя себя в экономике. Поэтому существенным отличием его от других ресурсов является свойство самореализации. Для всех иных ресурсов - земли, финансового капитала, труда требуется воздействие силы, внешней по отношению к ним: прежде всего инициативы предпринимателяорганизатора, где бы они оказались включенными в производственный процесс.

По мнению Ф. Найта, «цены производственных услуг “фиксируются” на рынке в ходе конкурентной борьбы предпринимателей, но доход предпринимателя не фиксирован: в него входит все, что остается после выплаты фиксированных доходов. Таким образом, исследовать его приходится косвенным путем, вникая в те силы, которыми определяются фиксированные доходы и соотнося их со всем продуктом предприятия или общества» [8]. Иными словами, это единственный ресурс, судить о наличии которого можно лишь по результатам его вовлечения в производство товаров или услуг. Результаты в таком разрезе про- являются в качестве ключевой компетенции (финансовой устойчивости) как итоговой комбинации всех прочих ресурсов, обеспечивающей получение ренты за их использование.

Ф. Найт указывает на различие предпринимательских функций и управленческого труда как такового, когда пишет, что «жалованье предпринимателя регулируется таким образом, что становится очевидной зависимость продолжительности его пребывания в должности от процветания предприятия под его руководством». Предпринимательский ресурс обеспечивает такое качество деятельности предприятием, при котором, по мнению Ф. Найта, сочетаются «способности» с «готовностью» [9]. Готовность использовать имеющиеся нефинансовые ресурсы сотрудниками, чья деятельность при этом обеспечивается собственными способностями как частью человеческих ресурсов, а также имеющейся в распоряжении персонала информационной базой, определяет объединение осязаемых нефинансовых ресурсов с предпринимательским ресурсом.

А. Чендлер, П. Хагстром и О. Солвелл [10] артикулируют идею, что для понимания процесса создания инноваций необходима теория создания знаний. Они выделяют два вида знаний, которые лежат в основе всей теории, - явные и скрытые. Понимание разницы между явным знанием и скрытым выступает для них ключевым аспектом отличия западного подхода к знаниям от японского. Создание знаний представляет собой не просто обучение у других или получение знаний извне. Кроме того, предприятие не может создавать знания без индивидов, но может поддерживать индивидов в этом процессе, поэтому знание должно быть создано в процессе взаимодействия групп индивидов внутри предприятия.

Увеличение стоимости компании Л. Эдвинссон напрямую связывал с инновационностью, обеспечившей такой рост капитализации, которую следует рассматривать как показатель оценки ее конкурентоспособности, в том числе и с точки зрения безопасности инвестируемых средств. Следовательно, знания, которыми располагает и которые использует компания, определяют уровень ее конкурентоспособности, являясь начальным и необходимым условием для усиления конкурентных преимуществ.

Р. Лессем выделяет три процесса в компании, в ходе которых создаются знания [11].

1) Создание новых знаний происходит в процессе деятельности при решении проблем как генеративный процесс.

2) Новое знание используется в продуктивном процессе, который служит основой для новых предложений.

3) После декларирования знания реализуется репрезентативный процесс, в котором знания, трансформированные в новые продукты, предлагаются потребителям. 


\section{Методология исследования}

В ходе реализации исследования нами были использованы:

- $\quad$ метод дедукции при схематическом построении архитектуры человеческих ресурсов и составляющих инструментария конкурентоспособности компании;

- $\quad$ метод индукции при определении элементов человеческого капитала;

- абстрагирование в процессе выявления трансформации нефинансовых ресурсов в финансовый капитал;

- $\quad$ анализ теоретических подходов в международном опыте страховой бизнес-практики.

\section{Результаты исследования}

Рост капитала страховой компании может осуществляться через финансовые ресурсы за счет изменения дивидендной политики и увеличения акционерного капитала, что ограничивает топ-менеджмент в использовании инструментов управления и развития компании.

Возможность собственного капитала к самовозрастанию характеризует приемлемый уровень образования чистой (нераспределенной) прибыли страховщика, его способность поддерживать финансовое равнове- сие за счет собственных источников. Снижение в общем объеме удельного веса собственного капитала до некого критического предела свидетельствует о потере финансовой независимости при ведении страхового предпринимательства и возрастании роли внешних источников финансирования, что подтверждает важность диверсификации ресурсов для роста капитализации [1].

Предпринимательский ресурс может стать капиталом только в объединении с прочими осязаемыми нефинансовыми ресурсами, реализуясь в управленческих компетенциях, проявляющихся в первую очередь в рыночном успехе компании и росте ее клиентской базы, что означает рост удовлетворенности ключевых стейкхолдеров страховщика: страхователей и акционеров. При этом предпринимательский ресурс, имея персонифицированную форму, определяет прежде всего человеческий капитал, где в дальнейшем переносится для создания его интеллектуальной или предпринимательской формы. В соответствии со взглядами на предпринимательство как на фактор производства, его основной характеристикой является способность к инновациям. Наличие у страховой компании способности к инновациям обеспечивает постоянство процесса новых эффективных инструментов и продуктов, позволяющих сохранять положительный тренд развития компании в условиях изменений внешней и внутренней среды.

Рисунок 2. Модель трансформации нефинансовых ресурсов в финансовый капитал

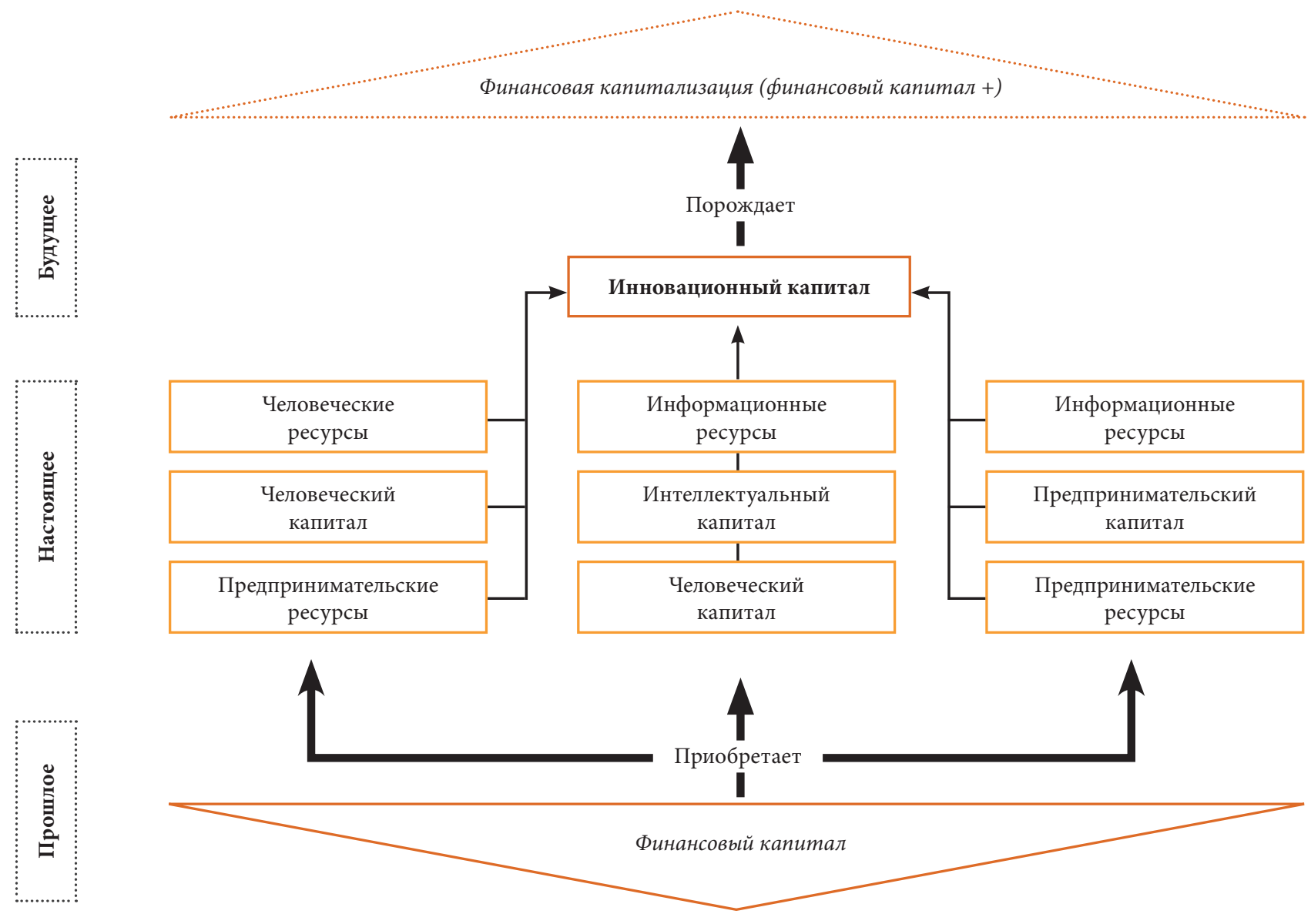

Источник: авторская разработка. 
В формировании инновационного капитала, обеспечивающего квазимонопольную ренту, предпринимательский капитал участвует одновременно с интеллектуальным капиталом как базой создания инноваций и человеческим капиталом как носителем предпринимательской инициативы.

Учитывая указанные выше факторы, мы предлагаем архитектуру трансформации во времени нефинансовых ресурсов в финансовый капитал (рис. 2).

Предпринимательский капитал является пересечением человеческого и интеллектуального капиталов. Каждый из используемых компанией нефинансовых ресурсов, кроме предпринимательского, имеет осязаемую форму. При соединении с предпринимательским ресурсом они порождают неосязаемый капитал, обеспечивающий маркетинговую капитализацию компании. Что касается стоимости осязаемых нефинансовых ресурсов, она может быть сформирована на основе затрат на оплату таких ресурсов, их привлечения или создания. Сумма указанной оплаты участвует при расчете прибыли компании до налогообложения NOPAT в системе МСФО.
Особенность осязаемых качеств используемых нефинансовых ресурсов состоит в том, что они могут контролироваться менеджментом до начала вовлечения их в страховые бизнес-процессы. Наличие неосязаемых качеств, возникших при соединении с предпринимательским ресурсом, может быть оценено только при получении финансовых результатов от их использования: путем оценки прибыли (NOPAT), добавленной стоимости (EVA) или уровня маркетинговой капитализации (изменения рыночной стоимости компании).

Структурируя сущностное содержание понятия «человеческие ресурсы» [12-14] в корпорации, мы предлагаем следующее схематическое представление осязаемых характеристик (рис. 3).

Соединение их с предпринимательским ресурсом менеджмента формирует в качестве синергетического результата человеческий капитал, объединяясь со следующими неосязаемыми качествами, входящими в состав ресурсов, и образуя новое качество (рис. 4).

Информационные ресурсы страховой организации также имеют осязаемые характеристики [15-18], peализуемые, например, в базе корпоративных знаний (рис. 5).

Рисунок 3. Структура осязаемых характеристик человеческих ресурсов

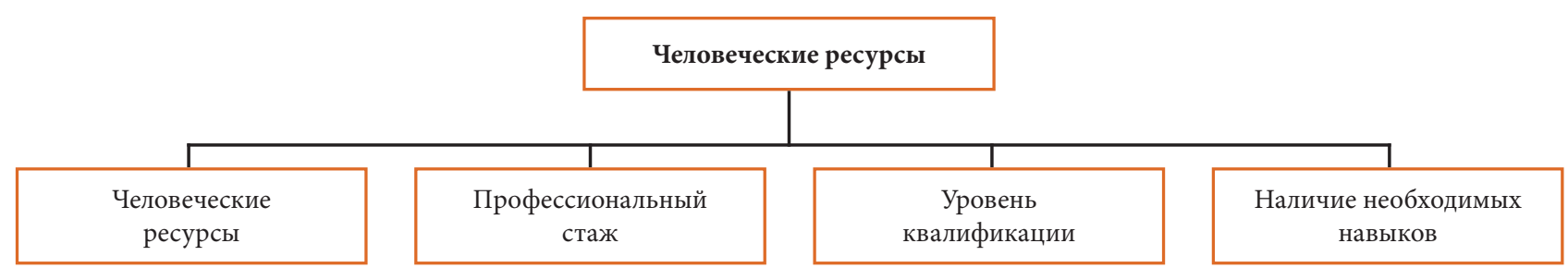

Источник: разработано на основе [12-14].

Рисунок 4. Структура человеческого капитала

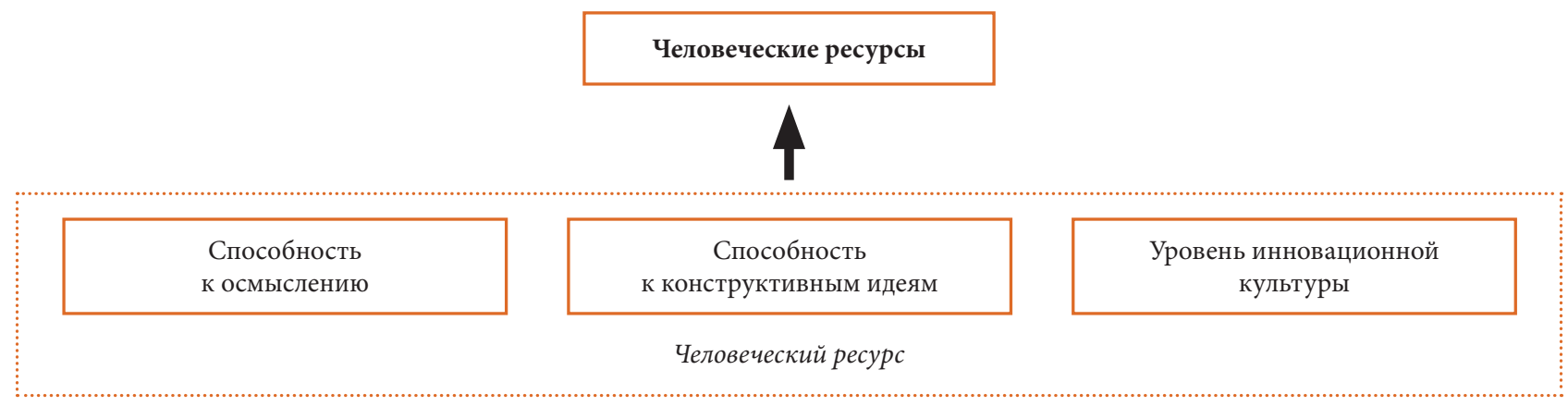

Источник: авторская разработка. 
Рисунок 5. Структура информационных ресурсов

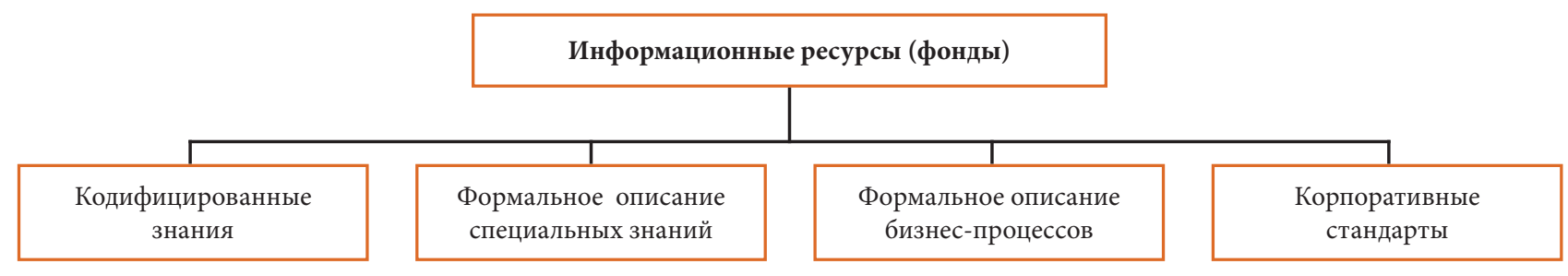

Источник: разработано на основе [15-18].

Рисунок 6. Структура интеллектуального капитала

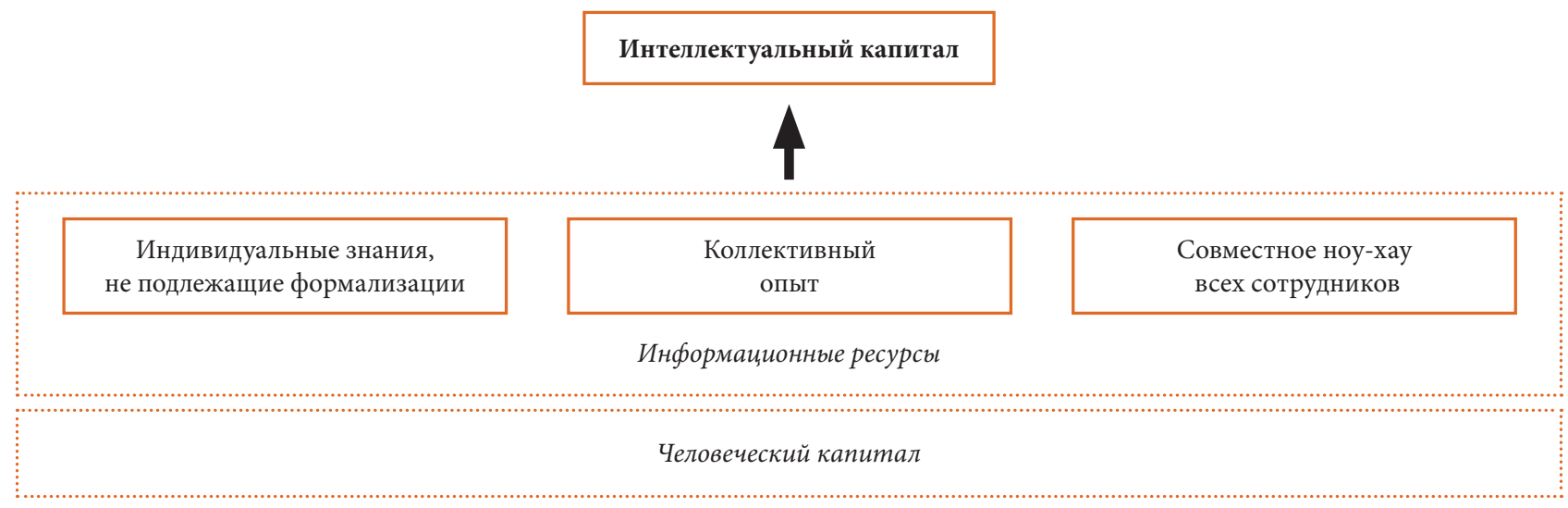

Источник: авторская разработка.

При пересечении с человеческим капиталом, включающим вовлеченные в производство способности всех сотрудников, информационные ресурсы трансформируются в интеллектуальный капитал, участвующий в производстве стоимости страховой деятельности (рис. 6).

Все прочие формы капитала, определения которых встречаются в специальной литературе, в целом представляют собой конкретизацию пересечений различных секторов интеллектуального капитала с человеческим:

- отношенческий капитал, проявляющийся в процессе пересечения знаний и навыков, составляющих сущность человеческого капитала, с той частью интеллектуального капитала, которая содержит принятые компанией приемы и методы работы с клиентами или партнерами, корпоративную практику по организации взаимоотношений с контрагентами и созданию позитивных коммуникаций компании на рынке [19];

- $\quad$ организационный капитал, который проявляется в процессе пересечения знаний и навыков, составляющих сущность человеческого капитала менеджмента, с той частью интеллектуального капитала, которая содержит приемы и методы, объединяющие всех лиц, которые участвуют в работе компании для достижения единых корпоративных целей и создают внутреннюю непротиворечивую корпоративную культуру, т.е. частью интеллектуального капитала, обеспечивающего высокоэффективную организационную структуру компании [20];

- структурный капитал, проявляющийся в процессе пересечения знаний и навыков, составляющих сущность человеческого капитала, с той частью интеллектуального, которая касается эффективной структуры корпоративной информации, отражающих ее баз данных, стандартизованных описаний бизнес-процессов, корпоративных стандартов, бренда и иных «нематериальных активов», остающихся в распоряжении компании даже в отсутствии сотрудников [21].

Выделение подобных форм капитала имеет смысл тогда, когда конкретные секторы интеллектуального или человеческого капитала являются объектами для реализации индивидуальной маркетинговой стратегии компании в целях повышения ее рыночной стоимости. Уникальность комбинаций ресурсов компании - это база для производства инноваций как новшеств по определению. Аргументом в пользу такого утверждения служит то, что такая уникальная комбинация является, во-первых, новой, поскольку уникальна, а, во-вторых, - эффективной, в силу определения ее как основы для создания ключевой компетенции. Поскольку каждый из ресурсов, участвующих в создании этой базы, легко доступен, то ее формирование обеспечивается именно «живым знанием», т.е. информацией, ценность которой реализуется ее живым носителем - специалистом, получившим ее в результате образования, опыта и деловой интуиции. 
Особенно ценны такие уникальные комбинации ресурсов в сфере интеллектуальных услуг, использующих высокоспецифичные и индивидуально накопленные знания. К сфере таких услуг относится и сфера страхования [22].

Именно в ходе этих процессов создается знание, которое в итоге проявляется в виде предложения нового товара или услуги для потребителей, что для страховой компании трансформируется в портфель уникальных страховых услуг.

Мы определяем систему факторов, обеспечивающих формирование ключевой компетенции страховой компании как основы ее рыночной конкурентоспособности, включив в нее фактор «знания», который в условиях современной экономики может быть признан основополагающим условием устойчивого развития организаций (рис. 7).

Рисунок 7. Знания как базис формирования конкурентоспособности страховой компании, работающей в условиях непрерывных изменений

\begin{tabular}{|c|}
\hline Конкурентоспособность \\
\hline $\begin{array}{c}\text { Ключевая компетенция: финансовая устойчивость, } \\
\text { рост экономического капитала }\end{array}$ \\
\hline Формирует \\
\hline Инновационность \\
\hline Порождают \\
\hline Знания \\
\hline
\end{tabular}

Источник: авторская разработка.

Если согласиться с оценкой знаний как базиса в обеспечении стабильности инновационного развития компании в условиях непрерывных изменений, то остро встает вопрос о специфическом управлении по увеличению потока таких знаний в организацию. Знания, умения и навыки конкретных сотрудников, вовлеченных в творческий процесс, формируют основу инновационности фирмы. Технологическая составляющая без творчества во многом становится неструктурированным набором знаний, которые сложно трансформировать в фундамент инновационного развития корпорации. Способность к созидательному творчеству у сотрудников - это и есть практическая реализация живого знания в компании. Составляющая творчества благоприятно влияет на устойчивость бизнес-модели, где в основе лежит «живой» и гибкий интеллектуальный капитал [23].

Страховщик, основной деятельностью которого является «обработка» риска, работает в недетерминированных условиях, с негарантированным информационным обеспечением, т.е. в условиях неопределенности. Принимаемые страховыми специалистами решения всегда являются до некоторой степени «предпринимательскими» и даже «инновационными» в связи с оригинальностью и неповторимостью каждого принимаемого риска, каким бы типовым он ни был. Страховые операции, от оформления страхового продукта до организации выплат выгодоприобретателям, не могут считаться итерационными, поскольку призваны обеспечить индивидуальные страховые потребности для индивидуальных физических или юридических лиц. Таким образом, для обеспечения своей ключевой компетенции страховщик должен обладать в качестве ресурсов специалистами, использующими знания, опыт, деловую интуицию, особо точную, релевантную информацию, а также организовать высокую эффективность комбинаций человеческих и информационных ресурсов с использованием технических, организационных, коммуникационных и мотивационных инструментов. Такие операционные действия гарантируют страховщику адекватность страхового капитала и прибыль как эффект на эффективное использование ресурсной базы, что характерно для рикардианской ренты страховщика. Для такого типа ренты характерно использование предпринимательского ресурса страховой компании, функционирующего на пересечении с человеческим и информационным ресурсом как предпринимательский капиталом.

Особое значение нефинансовые формы капитала имеют, на наш взгляд, для компаний, не достигших уровня крупных игроков на рынке и находящихся в процессе становления или ограничивающих свою деятельность конкретным регионом. В условиях конъюнктуры российского рынка это компании средних региональных страховщиков, основным источником развития которых служат преимущественно нефинансовые ресурсы, где эффективность использования оценивается через рост отдачи на затраты, т.е. через повышение рентабельности капитала.

Ориентация компании на удовлетворение страховых потребностей за счет предпринимательских инновационных подходов к созданию страховых услуг обеспечит возможность установления их рыночной цены на уровне, включающем дополнительную ренту. Рост финансовой отдачи от реализации бизнес-процессов также формирует дополнительную ренту для страховщика. Если рента будет присваиваться страховщиком не полностью, а использоваться для некоторого снижения цены страховых услуг на рынке, то компании будет обеспечен коммерческий успех.

На практике успешность предложенной модели деятельности страховой компании обусловлена многими 
факторами. Кроме типичных рыночных колебаний спроса и предложения, на результативность деятельности влияет уровень экспертизы топ-менеджеров, как фактор более влиятельный, чем финансовая архитектура компании [24], потребности и доверие потребителей, что доказано через факторный анализ в [25], а также ориентирование стратегии на стабильность в долгосрочной перспективе. Это в том числе снижает колебания рейтинга компании, а значит, влияет на указанное ранее доверие клиентов [26].

Ограничения предложенной модели концентрируются в рамках влияния культурологических факторов, определяющих специфику рынка. Согласно исследованию [27] Россия попадает в кластер стран с низким уровнем развития страховой отрасли, наряду с Турцией и Мексикой, но обладает большим потенциалом развития в связи с тем, что относится к развивающимся рынкам, где культура страхования пока находится на более низком уровне, чем в странах с развитыми рынками страхования. Таким образом, ключевым фактором влияния является культура страхования в стране, а значит, поведение страхователей на рынке, их уровень знаний о страховых инструмента, доверие к страховщикам и готовность передавать свои активы на рынок. Следовательно, предложенная модель ограничивается существующей конъюнктурой российского рынка и будет нуждаться в точечной адаптации при изменении интересов главных стейкхолдеров страховой компании, от которых зависит доступ компании к финансовым ресурсам страхователей.

\section{Заключение}

Высокий уровень капитализации страховой компании обеспечивает развитие ее эффективной инвестиционной политики. Рост капитализации демонстрирует улучшение финансового положения компании, укрепление их финансовой устойчивости и снижение риска банкротства.

Рассмотрение страховой компании как комбинации всех ее ресурсов позволяет отследить наступление стоимостной синергии (когда стоимость такой комбинации выше, чем сумма стоимостей всех ее элементов). Источниками появления синергетического эффекта служат нефинансовые формы капитала, воплощающиеся в создании и реализации новых маркетинговых инструментов для роста рыночной доли.

Главный вывод состоит в необходимости определения страховыми компаниями особо важной роли персонифицированных знаний, высокого уровня образования персонала и развития узкопрофильных навыков сотрудников, как структурного элемента своей корпоративной стратегии, поскольку именно на данной базе развивается и пополняется инновационный капитал компании.

Абсолютная потребность в постоянном поиске наиболее эффективных комбинаций ресурсов приводит к логичному следствию, что в деятельности страховщика как финансового посредника источником прибыли или ренты является именно деятельность по нахождению оптимальных путей удовлетворения страховых потребностей путем перераспределения полученных на страховом рынке средств самих же потребителей. Это означает, что эффективность комбинации ресурсов страховщика определяется успешностью его работы на рынке за счет создания эффективных маркетинговых инструментов, обеспечивающих ему капитализацию, т.е. рост стоимости страховой фирмы, которую справедливо можно идентифицировать как маркетинговую капитализацию.

\section{Список литературы}

1. Хрусталева Н.Е., Грищенко Ю.И. Оценка уровня капитализации страховых компаний. Современные научные исследования и инновации. 2015;(12):808-813.

2. Эдвинссон Л., Мэлоун М. Интеллектуальный капитал. Определение истинной стоимости компании. Новая постиндустриальная волна на Западе. Антология. Иноземцев В.Л., ред. Пер. с англ. М.: Academia; 1999:429-447.

3. Weizsäcker E. von, Lovins A.B., Lovins L.H. Factor four: Doubling wealth, halving resource use. A new report to the Club of Rome. London, New York: Earthscan Publications Ltd.; 1998. 351 p.

4. Edvinsson L., Malone M. Intellectual capital: Realizing your company's true value by finding its hidden brainpower. New York: HarperBusiness; 1997. 240 p.

5. Жилинский С.Э. Предпринимательское право (правовая основа предпринимательской деятельности). М.: Норма; 2000. 672 c. URL: http://www. bibliotekar.ru/predprinimatelskoe-pravo/index.htm (дата обращения: 12.02.2019).

6. Лапуста М.Г., Поршнев А.Г., Старостин Ю.Л., Скамай Л.Г. Малое предпринимательство. М.: Инфра-М; 2007. 390 с.

7. Адизес И.К. Управление жизненным циклом корпораций. Пер. с англ. М.: Манн, Иванов и Фербер; 2015. 512 c.

8. Колесникова Ю.С., Валеев Э.Р. Структура нематериального капитала. Экономические науки. 2014;(121):15-18.

9. Найт Ф.Х. Риск, неопределенность и прибыль. Пер. с англ. М.: Дело; 2003. 360 с. URL: http://www. bibliotekar.ru/biznes-47/11.htm (дата обращения: 20.02.2019).

10. Chandler A.D., Hagström P., Sölvell Ö., eds. The dynamic firm: The role of technology, strategy, organization and regions. Oxford, New York: Oxford University Press; 1999. 451 p. 
11. Lessem R. Managing in Four Worlds: Culture, strategy and transformation. Long Range Planning. 2001;34(1):9-32. DOI: 10.1016/S00246301(00)00098-4

12. Армстронг М. Практика управления человеческими ресурсами. 8-е изд. Пер. с англ. СПб.: Питер; 2007. 783 с.

13. Кравчук М. Как эффективно организовать управление человеческими ресурсами. HR-Portal. 2013. URL: http://www.hr-portal.ru/article/kak-effektivnoorganizovat-upravlenie-chelovecheskimi-resursami (дата обращения: 5.02.2019).

14. Разнодежина Э.Н. Место человеческих ресурсов в достижении качества в промышленности. Мат. VI Междунар. конф. “Стратегия качества в промышленности и образовании” (Варна, 4-11 июня 2010). (в 4-х т.). Т. 1. 2000:461.

15. Иноземцев В.Л. За пределами экономического общества. М.: Academia, Наука; 2002. 640 с.

16. Леонтьев Б.Б. Цена интеллекта. Интеллектуальный капитал в российском бизнесе: Оценка, ориентирование, моделирование, защита прав. М.: Акционер; 2002. 196 с.

17. Лосева О.В., Дресвянников В.А. Человеческий интеллектуальный капитал: теория, методология и практика оценки. М.: Русайнс; 2017. 288 с.

18. Стюарт Т.А. Интеллектуальный капитал. Новый источник богатства организации. Пер. с англ. М.: Поколение; 2007. 368 с.

19. Mu J., Peng G., Love E. Interfirm networks, social capital, and knowledge flow. Journal of Knowledge Management. 2008;12(4):86-100. DOI: $10.1108 / 13673270810884273$

20. Bounfour A., ed. Organizational capital: Modelling, measuring and contextualising. London, NewYork: Routledge; 2008. 320 p.
21. Drucker P.F. The age of social transformation. The Atlantic Monthly. 1994;274(5):53-80. URL: http:// homepages.se.edu/cvonbergen/files/2015/12/TheAge-of-Social-Transformation.pdf

22. Котлобовский И., Лайков А., Рыбаков С., Третьяков К. К вопросу о стратегии развития отечественного страхования. Страховое дело. 2007;(6):8-16.

23. Байбурина Э.Р. Методы анализа интеллектуального капитала для современного устойчивого развития компании. Корпоративные финансы. 2007;1(3):85-101. DOI: 10.17323/j.jcfr.20730438.1.3.2007.85-101

24. Adams M., Jiang W. Do outside directors influence the financial performance of risk-trading firms? Evidence from the United Kingdom (UK) insurance industry. Journal of Banking \& Finance. 2016;64:3651. DOI: 10.1016/j.jbankfin.2015.11.018

25. Sharma A., Jadi D.M., Ward D. Evaluating financial performance of insurance companies using rating transition matrices. The Journal of Economic Asymmetries. 2018;18(e00102). DOI: 10.1016/j. jeca.2018.e00102

26. Felício J.A., Rodrigues R. Organizational factors and customers' motivation effect on insurance companies' performance. Journal of Business Research. 2015;68(7):1622-1629. DOI: 10.1016/j. jbusres.2015.02.006

27. Буданова М.М., Пересветов С.Б. Исследование страховых рынков 31 страны на базе страховых показателей и выявление места России в кластерной иерархии с помощью кластерного анализа в среде R. Корпоративные финансы. 2017;11(2):96115. DOI: 10.17323/j.jcfr.2073-0438.11.2.2017.96-115 


\title{
Role of Non-financial Resources in the Capitalization of Insurance Company
}

\author{
Lyudmila Tsvetkova \\ Candidate of Economic Sciences, Associate Professor \\ ORCID \\ E-mail: tsvetkova1501@gmail.com \\ Department of risk management and insurance, MGIMO University, Moscow, Russi
}

Journal of Corporate Finance Research, Vol. 13, No. 2, pp. 50-65 (2019)

DOI: https://doi.org/10.17323/j.jcfr.2073-0438.13.2.2019.50-65

Received 24 March 2019 | Peer-reviewed 10 April 2019 | Accepted 3 June 2019 


\section{Role of Non-financial Resources in the Capitalization of Insurance Company}

\section{Abstract}

The aim of this article is to conduct a conceptual study on the role of non-financial resources in the capitalization of an insurance company. The effectiveness of a company's non-financial resources is based on its ability to generate financial capital from them, and a company's employees and clients are the embodiment and creators of the most fundamental non-financial resources. We postulate that the needs of insurance companies to increase their capitalization is first addressed by ensuring adequate and quality capital is in place to maintain day to day business, and ensuring this capital is effectively structured.

Therefore, our evaluation of the effectiveness of capital structure is conducted according to the resource based view of competitiveness. We explore the hypothesis that a company's non-financial resources may be converted into financial capital when they are combined with an entrepreneurial influence - in this case, either an employee or a manager.

We apply the following diverse methodologies. First, a deductive approach is used to construct a virtual human resources architecture, which allows us to allocate conceptual corporate tools for improving competitiveness. Next, using an inductive method, we determine the relevant components of human capital. The abstraction method is applied to demonstrate a situation whereby non-financial resources transform into financial capital. Finally, we utilize an analytical methodology to evaluate the respective theoretical approaches used by international insurance companies.

We establish our methodological prerequisites in a conceptual model and successfully determined the onset of cost synergy as a combination of all company resources. Further, we identify the need for insurance companies to introduce personalized knowledge into corporate strategy. We thereby vaidate our hypothesis and confirm that the knowledge and experience of insurance companies' employee and client bases represents an essential non-finanical resource, and constitutes a legitimate structural element through which innovation capital may be developed and replenished.

The novelty of our study is represented by its practical and theoretical applications. As our results indicate, we successfully outline a universal conceptual approach that enables an increase in capitalization regardless of the market specialization in which an insurance company operates. As such, not only can our findings be directly implemented by insurance companies as a new management approach in order to improve corporate efficiency and strategic stability, but can be seen to have immediate bearing on consumer and business interests beyond the insurance industry, as well as informing further theoretical strategy development in academia.

Keywords: resource-based view, non-financial resources, innovation, venture capital JEL classification: G34, M14, O16 


\section{References}

1. Khrustaleva N.E., Grishchenko Yu.I. Assessment of the level of capitalization of insurance companies. Sovremennye nauchnye issledovaniya i innovatsii = Modern Scientific Researches and Innovations. 2015;(12):808-813. (In Russ.).

2. Edvinsson L., Malone M. Intellectual capital: Realizing your company's true value by finding its hidden brainpower. Transl. from Eng. In: Inozemtsev V.L., ed. A new post-industrial wave in the West. Anthology. Moscow: Academia; 1999:429-447. (In Russ.).

3. Weizsäcker E. von, Lovins A.B., Lovins L.H. Factor four: Doubling wealth, halving resource use. A new report to the Club of Rome. London, New York: Earthscan Publications Ltd.; 1998. 351 p.

4. Edvinsson L., Malone M. Intellectual capital: Realizing your company's true value by finding its hidden brainpower. New York: HarperBusiness; 1997. $240 \mathrm{p}$.

5. Zhilinskii S.E. Entrepreneurial law (Legal basis for entrepreneurial activity). Moscow: Norma; 2000. 672 p. URL http://www.bibliotekar.ru/ predprinimatelskoe-pravo/index.htm (accessed on 12.02.2019). (In Russ.).

6. Lapusta M.G., Porshnev A.G., Starostin Yu.L., Skamai L.G. Small business. Moscow: Infra-M; 2007. 390 p. (In Russ.).

7. Adizes I.K. Managing corporate lifecycles. Transl. from Eng. Moscow: Mann, Ivanov \& Ferber; 2015. 512 c. (In Russ.).

8. Kolesnikova Yu.S., Valeev E.R. The structure of intangible capital. Ekonomicheskie nauki = Economic Sciences. 2014;(121):15-18. (In Russ.).

9. Knight F.H. Risk, uncertainty and profit. Transl. from Eng. Moscow: Delo; 2003. 360 p. URL: http:// www.bibliotekar.ru/biznes-47/11.htm (accessed on 20.02.2019). (In Russ.).

10. Chandler A.D., Hagström P., Sölvell Ö., eds. The dynamic firm: The role of technology, strategy, organization and regions. Oxford, New York: Oxford University Press; 1999. $451 \mathrm{p}$.

11. Lessem R. Managing in Four Worlds: Culture, strategy and transformation. Long Range Planning. 2001;34(1):9-32. DOI: 10.1016/S00246301(00)00098-4

12. Armstrong M. Armstrong's handbook of human resource management practice. $8^{\text {th }} \mathrm{ed}$. Transl. from Eng. St. Petersburg: Piter; 2007. 783 p. (In Russ.).
13. Kravchuk M. How to effectively manage human resources. HR-Portal. 2013. URL: http://www. hr-portal.ru/article/kak-effektivno-organizovatupravlenie-chelovecheskimi-resursami (accessed on 5.02.2019). (In Russ.).

14. Raznodezhina E.N. The place of human resources in achieving quality in industry. In: Proc. $6^{\text {th }}$ Int. conf. "Quality strategy in industry and education" (Varna, 4-11 June 2010). (in 4 vols.). Vol. 1. 2000:461. (In Russ.).

15. Inozemtsev V.L. Beyond economic society. Moscow: Academia, Nauka; 2002. 640 p. (In Russ.).

16. Leont'ev B.B. The value of intellect. Intellectual capital in Russian business: Assessment, orientation, modeling, protection of rights. Moscow: Aktsioner; 2002. 196 p. (In Russ.).

17. Loseva O.V., Dresvyannikov V.A. Human intellectual capital: Theory, methodology and practice of evaluation. Moscow: RuScience; 2017. 288 p. (In Russ.).

18. Stewart T.A. Intellectual capital: The new wealth of organizations. Transl. from Eng. Moscow: Pokolenie; 2007. 368 p. (In Russ.).

19. Mu J., Peng G., Love E. Interfirm networks, social capital, and knowledge flow. Journal of Knowledge Management. 2008;12(4):86-100. DOI: $10.1108 / 13673270810884273$

20. Bounfour A., ed. Organizational capital: Modelling, measuring and contextualising. London, NewYork: Routledge; 2008.320 p.

21. Drucker P.F. The age of social transformation. The Atlantic Monthly. 1994;274(5):53-80. URL: http:// homepages.se.edu/cvonbergen/files/2015/12/TheAge-of-Social-Transformation.pdf

22. Kotlobovskii I., Laikov A., Rybakov S., Tret'yakov K. On Russian insurance development strategy. Strakhovoe delo = Insurance Business. 2007;(6):8-16. (In Russ.).

23. Baiburina E.R. Methods of analysis of intellectual capital for the modern sustainable development of the company. Korporativnye finansy = Journal of Corporate Finance Research. 2007;1(3):85-101. DOI: 10.17323/j.jcfr.2073-0438.1.3.2007.85-101 (In Russ.).

24. Adams M., Jiang W. Do outside directors influence the financial performance of risk-trading firms? Evidence from the United Kingdom (UK) insurance industry. Journal of Banking \& Finance. 2016;64:3651. DOI: 10.1016/j.jbankfin.2015.11.018 
25. Sharma A., Jadi D.M., Ward D. Evaluating financial performance of insurance companies using rating transition matrices. The Journal of Economic Asymmetries. 2018;18(e00102). DOI: 10.1016/j. jeca.2018.e00102

26. Felício J.A., Rodrigues R. Organizational factors and customers' motivation effect on insurance companies' performance. Journal of Business Research. 2015;68(7):1622-1629. DOI: 10.1016/j. jbusres.2015.02.006

27. Budanova M.M., Peresvetov S.B. Insurance markets' research based on insurance indicators data for 31 countries and identification of Russia's place in hierarchical clustering in $\mathrm{R}$ studio environment. Korporativnye finansy = Journal of Corporate Finance Research. 2017;11(2):96-115. DOI: 10.17323/j. jcfr.2073-0438.11.2.2017.96-115 (In Russ.). 